\title{
Valor alimentício das silagens de milho e de sorgo e sua influência no desempenho de vacas leiteiras ${ }^{1}$
}

\section{Willian Gonçalves do Nascimento ${ }^{2}$, Ivanor Nunes do Prado ${ }^{3}$, Clóves Cabreira Jobim ${ }^{3}$, Jean Claude Emile ${ }^{4}$, Fabien Surault ${ }^{4}$, Christian Huyghe ${ }^{4}$}

\author{
1 Pesquisa financiada pela CAPES/COFECUB. \\ 2 Instituto Agronômico do Paraná, Paranavaí - PR. \\ 3 PPZ/Universidade Estadual de Maringá. Bolsista do CNPq. \\ ${ }^{4}$ Institut National de la Recherche Agronomique, 86600, Lusignan, França.
}

RESUMO - Objetivou-se avaliar os efeitos das silagens de sorgo granífero, sorgo sacarino e milho sobre a ingestão, produção e composição química do leite e a digestibilidade dos nutrientes em vacas em lactação. Foram utilizadas 24 vacas da raça Prim'Holstein (PO), divididas em três lotes de oito vacas para avaliação das seguintes silagens: silagem de milho (SM); silagem de sorgo granífero (SG); e silagem de sorgo sacarino (SS). As silagens foram fornecidas à vontade com dois concentrados comerciais, distribuídos de acordo com o nível de produção leiteira. A silagem de sorgo granífero promoveu maior ingestão de MS (22,98 kg/dia) em comparação às silagens de milho (21,95 kg/dia) e de sorgo sacarino (19,43 kg/dia). A ingestão de água (litros/vaca/dia) foi semelhante entre os animais alimentados com silagem de milho $(71,91)$ e de sorgo granífero $(76,30)$ e menor nos animais alimentados com silagem de sorgo sacarino (56,95). A produção de leite total $(28,81 ; 24,69$ e $24,14 \mathrm{~kg} / \mathrm{dia})$ corrigida a $4 \%$ de gordura $(30,65 ; 25,63$ e $26,10 \mathrm{~kg} / \mathrm{dia})$ foi maior entre as vacas alimentadas com silagem de milho, no entanto, a porcentagem de gordura do leite das vacas alimentadas com silagem de sorgo sacarino foi maior (4,56\%) em comparação àquelas alimentadas com silagem de milho (4,39\%) e silagem de sorgo granífero (4,31\%). A porcentagem de proteína foi maior $(3,25 \%)$ no leite das vacas alimentadas com silagem de milho, intermediária no leite das vacas alimentadas com silagem de sorgo sacarino $(3,05 \%)$ e menor no leite das vacas alimentadas com silagem de sorgo granífero $(2,97 \%)$. Os coeficientes de digestibilidade dos nutrientes foram maiores nas vacas alimentadas com a ração à base de silagem de sorgo sacarino em comparação às rações à base de silagem de sorgo granífero e de milho.

Palavras-chave: desempenho zootécnico, digestibilidade, sorgo sacarino, vacas em lactação

\section{Nutritive value of corn and sorghum silages and its influence on dairy cow performance}

\begin{abstract}
The effect of feeding grain sorghum silage, sweet sorghum silage, and corn silage on intake, milk production, milk composition, and nutrient digestibility of lactation dairy cows was evaluated. Twenty-four Prim'Holstein (PO) cows were used, forming three groups of eight cows each. The experimental treatments were: 1) corn silage; 2) grain sorghum silage; and 3) sweet sorghum silage, fed ad libitum, with two commercial concentrates, distributed following the cow milk production. Grain sorghum silage promoted greater DM intake (22.98 kg/day) compared to corn silage (21.95 kg/day), and sweet sorghum silage (19.43 kg/day). Dry matter intake was greater for corn silage than for sweet sorghum silage. Water intake (L/cow/day) was similar for the animals fed corn silage (71.91) and grain sorghum silage (76.30), and both were greater than the water intake of animals fed sweet sorghum silage (56.95). Total milk production $(28.81 ; 24.69$ and $24.14 \mathrm{~kg} / \mathrm{day})$, $4 \%$ fat corrected milk $(30.65 ; 25.63$ and $26.10 \mathrm{~kg} /$ day $)$, and milk chemical composition was greater for cows fed corn silage when compared to the ones receiving grain sorghum silage and sweet sorghum silage. Cows fed sweet sorghum silage, but showed higher milk fat percentage (4.56\%) compared to cows fed corn silage (4.39\%) or grain sorghum silage (4.31\%). Milk protein concentration was higher for cows fed corn silage (3.25\%), intermediate for cows fed sweet sorghum silage (3.05\%), and lower for the ones fed grain sorghum silage (2.97\%). Nutrient digestibility coefficients were greater for cows fed sweet sorghum silage compared to other silages.
\end{abstract}

Key Words: animal performance, dairy cows, digestibility, sweet sorghum

Este artigo foi recebido em 1/12/2006 e aprovado em 27/11/2007.

Correspondências devem ser enviadas parainprado@uem.br. 


\section{Introdução}

Considerada uma das alternativas para a alimentação animal, a cultura do sorgo forrageiro tem papel importante na metade do sul da França por sua capacidade de adaptação à seca, fator limitante à cultura do milho, garantindo melhores resultados econômicos à atividade.

Na França, durante muito tempo, a utilização do sorgo forrageiro foi praticada com o Sudam grass. A partir dos anos 80, com o aparecimento de novas variedades (Sorghum bicolor) com teores reduzidos de tanino e de novas tecnologias no processo de ensilagem, a cultura do sorgo teve seu mercado ampliado (Legarto, 2000).

Uma das formas de utilização desses materiais na alimentação de ruminantes é a ensilagem. No entanto, existem critérios para avaliar o valor nutritivo desses alimentos conservados, que, segundo Souza et al. (2003), são: consumo voluntário, digestibilidade e eficiência da utilização de nutrientes ingeridos. Bezerra et al. (2002) relataram que, em ruminantes, existem inúmeros fatores que interferem no consumo. Esses fatores de variação são fundamentais para o balanceamento das dietas. Um deles é a granulometria dos alimentos, que, segundo Sauvant (2000), tem influência direta na ruminação, ingestão e digestibilidade do alimento. Este autor ressalta que o tamanho da partícula de uma forragem determina as condições ruminais e, quando é pequeno, pode provocar redução do $\mathrm{pH}$ e da proporção de acetato.

Pesquisadores do Institut d'Élevage (1990) compararam 50 variedades de sorgo e de milho para silagem, obtidas em condições semelhantes, e constataram que a proporção de partículas finas é duas vezes maior no sorgo que no milho.

Nos ensaios sobre o consumo voluntário das silagens de sorgo e de milho em vacas leiteiras, não houve diferença no consumo entre estes dois tipos de forragem (3,3\% do peso corporal), fato relacionado aos baixos teores de MS das silagens (26 a 27\%), o que estaria de acordo com os resultados observados por McDonald et al. (1991).

A digestibilidade da planta inteira do sorgo granífero é influenciada pelo seu estado de maturidade (30 e $41 \%$ de MS). Os coeficientes da digestibilidade da matéria orgânica e da celulose bruta reduziram, respectivamente, 2,4 e 13 pontos percentuais (Legarto, 2000). Entretanto, Mizubuti et al. (2002) não observaram diferenças significativas da digestibilidade aparente da MS entre as silagens de milho e sorgo, mesmo com baixos teores de MS (29,56\% e 24,94\%, respectivamente).

Objetivou-se com este trabalho avaliar o efeito de silagens de sorgo granífero e sorgo sacarino e de milho como volumoso para vacas em lactação sobre o consumo voluntário, a produção e composição química do leite e a digestibilidade dos nutrientes das dietas.

\section{Material e Métodos}

O experimento foi conduzido na Unidade Experimental do INRA - Institut National de la Recherche Agronomique, Centro de Pesquisas Poitou-Charentes, localizada em Lusignan (Vienne, França - $15^{\circ}$ Leste, 45,26 Norte).

As culturas de sorgo e milho foram implantadas na primavera de 2003, ano caracterizado por uma primavera amena e de poucas chuvas, seguida de verão excepcionalmente quente. $\mathrm{O}$ mês de agosto foi muito atípico, com calor excessivo e temperatura média máxima de $31,9^{\circ} \mathrm{C}$ (Figura 1 , Estação Meteorológica INRA - Lusignan).

Para a cultura de milho e das variedades de sorgo, as exigências em nitrogênio foram determinadas utilizando-se o método dos balanços PcAZOTE ${ }^{\circledR}$, considerando os seguintes parâmetros: cultura precedente, histórico, nitrogênio remanescente e o objetivo de rendimento.

Os híbridos de sorgo utilizados foram: sorgo granífero Arakan ${ }^{\circledR}$ e sorgo sacarino Top silo ${ }^{\circledR}$, escolhidos de acordo com suas características de adaptação à seca e suas capacidades em produzir silagem de qualidade com rendimento elevado. O híbrido de milho utilizado como testemunha foi Cocagne ${ }^{\circledR}$.

As três silagens foram produzidas do mesmo modo, de forma a não ocasionar diferenças significativas nas etapas de corte (altura de corte, velocidade da máquina de corte), enchimento, compactação e fechamento do silo (silo tipo bunker).

As principais características de condução das culturas estão demonstradas na Tabela 1 . As avaliações de rendi-

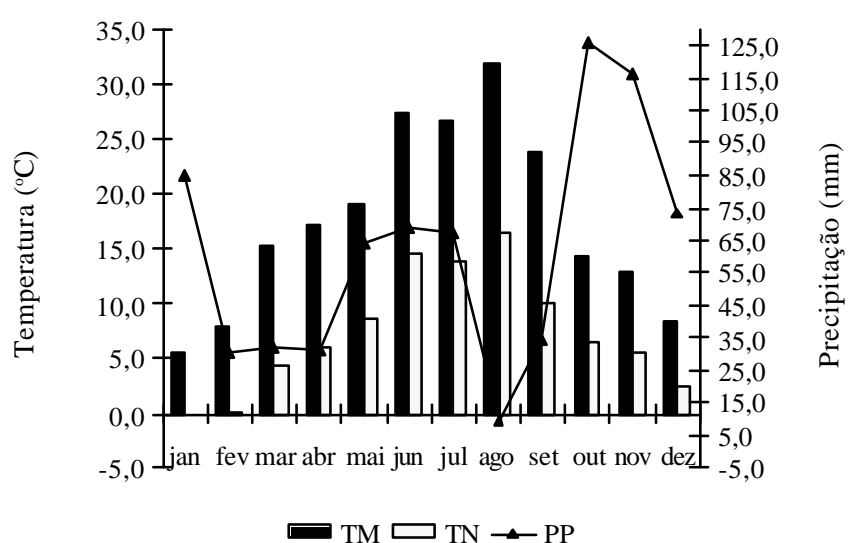

Figura 1 - Precipitação pluviométrica média (PP) e temperaturas máxima (TM) e mínima (TN). 
Tabela 1 - Principais características de condução das culturas de milho e dos sorgos

\begin{tabular}{|c|c|c|c|}
\hline \multirow[t]{2}{*}{ Característica } & \multicolumn{3}{|c|}{ Híbrido } \\
\hline & Cocagne ${ }^{\circledR}$ Milho** & Arakan ${ }^{\circledR}$ Sorgo granífero & Top silo ${ }^{\circledR}$ Sorgo sacarino \\
\hline Cultura antecedente & Trigo & Alfafa & Azevém \\
\hline Densidade (plantas/ha) & 100.000 & 375.400 & 200.000 \\
\hline Espaçamento & $0,75 \mathrm{~m}$ & $0,40 \mathrm{~m}$ & $0,75 \mathrm{~m}$ \\
\hline Data de semeadura & 24 de abril & 15 de maio & 14 de maio \\
\hline \multirow[t]{4}{*}{ Herbicida } & Atraphyt ${ }^{\circledR}$ (atrazine 2,5 1/ha) & \multicolumn{2}{|c|}{$\operatorname{Ramrod}^{\circledR}($ propachlore 6 1/ha) } \\
\hline & Lagon ${ }^{\circledR}($ isoxaflutole + aclonifen $0,7 \mathrm{l} / \mathrm{ha})$ & \multicolumn{2}{|c|}{ Pós-semeaduraFighter ${ }^{\circledR}$ (bentazone 2,5 1/ha) } \\
\hline & Frontière ${ }^{\circledR}($ dimethenamide 1,3 1/ha) & \multirow{2}{*}{\multicolumn{2}{|c|}{ Pós-emergente }} \\
\hline & $\begin{array}{l}\text { Pós-emergente } \\
\end{array}$ & & \\
\hline Modo de condução & Total $152 \mathrm{~mm}$ em 5 irrigações & \multicolumn{2}{|c|}{ Não irrigado } \\
\hline Ponto de corte (2003) & 30 de agosto & 26 de agosto & 25 de agosto \\
\hline Altura de corte* & 10 a $15 \mathrm{~cm}$ & & \\
\hline
\end{tabular}

mento e composição morfológica das culturas foram realizadas no momento do corte, uma vez que as amostragens das plantas foram feitas na linha sobre um comprimento de $3 \mathrm{~m}$ e com cinco repetições para cada cultura.

As plantas amostradas foram separadas em duas partes: parte grão: sabugo e grãos para o milho e as panículas do sorgo; parte não-grão: nesta fração foram incluídas todas as partes aéreas das plantas, incluindo, no caso do milho, as brácteas e as panículas. Após a separação, as partes foram pesadas individualmente para cada cultura

O teor de matéria seca foi determinado após secagem em estufa a $75-80^{\circ} \mathrm{C}$, por 48 horas. As amostras secas foram trituradas em moinho tipo martelo com peneira de crivo de $1 \mathrm{~mm}$ e armazenadas em potes plásticos para análises bromatológicas.

No experimento para avaliação do desempenho das vacas leiteiras, 24 animais da raça Prim'Holstein (PO) foram utilizados e separados em três lotes de oito animais (quatro primíparas e quatro multíparas), considerando os seguintes critérios: peso corporal (médio 635,5 kg), período de lactação (valor médio no início do experimento $=65$ dias) e produção de leite durante as quatro semanas pré-experimentais (valor médio $=30,6 \mathrm{~kg} / \mathrm{dia} /$ animal $)$.

$\mathrm{O}$ experimento para avaliação do desempenho animal foi realizadono período de novembro de 2003 a fevereiro de 2004, durante 103 dias. Após 15 dias de adaptação para que os animais pudessem, em estabulação livre, se familiarizar com as portas eletromagnéticas que davam acesso aos comedouros individuais e às rações experimentais, iniciou-se o ensaio, que foi dividido em quatro períodos de 22 dias.

Os animais foram pesados no início do experimento e ao final de cada período. As pesagens foram realizadas após a ordenha da manhã, durante dois dias consecutivos e os valores foram corrigidos, segundo o método de Chilliard et al. (1987), para as variações de conteúdo digestivo:

$\mathrm{PVc}=\mathrm{PV}-(4 * \mathrm{MSI})$

$\mathrm{PVc}=$ peso vivo corrigido $(\mathrm{kg})$;

$\mathrm{PV}=$ peso vivo bruto $(\mathrm{kg})$;

MSI = matéria seca ingerida $(\mathrm{kg})$.

Os tratamentos experimentais consistiram de: silagem de milho; silagem de sorgo granífero; e silagem de sorgo sacarino, fornecidas à vontade, com dois concentrados comerciais, um de equilíbrio (2,2 $\mathrm{kg}$ de MS/dia) e um de produção (1,9 a 4,7 kg de MS/dia), fornecido de acordo com a produção leiteira.

O concentrado produção foi distribuído durante as duas ordenhas diárias (7h30 e 16h30). A quantidade oferecida foi de $1,0 \mathrm{~kg}$ de concentrado para cada $2,5 \mathrm{~kg}$ de leite produzido acima de uma produção de $22,5 \mathrm{~kg}(50 \%$ durante a primeira e os $50 \%$ restantes durante a segunda ordenha). Considerando que, segundo Emile \& Barrière (1992), em vacas primíparas e multíparas ocorre redução de 2,0 a 2,5\%/semana na persistência da produção leiteira, as quantidades de concentrado foram calculadas de acordo com a produção média de leite de referência de cada animal. Para as vacas primíparas, na primeira semana de cada mês, realizou-se reajuste de $2,0 \mathrm{~kg}$ na quantidade de concentrado, além do ofertado para produção de leite para suprir as necessidades decorrentes do crescimento (Jarrige, 1988).

A quantidade de silagem distribuída foi calculada diariamente, considerando uma sobra de $10 \%$ de MS ofertada em relação ao consumo. A quantidade de silagem ofertada cada dia foi calculada considerando o ingerido no dia 
anterior. As rações foram balanceadas em energia e em proteína, por meio da inclusão de cevada $(0,5$ e $1,0 \mathrm{~kg} / \mathrm{dia}$ nas dietas com as silagens de sorgo granífero e de sorgo sacarino, respectivamente) e de uréia (50 g na dieta com silagem de milho), de acordo com recomendações preconizadas por Jarrige (1988).

As produções leiteiras individuais foram registradas a cada ordenha (7h30 e 16h30) com auxílio de coletores volumétricos ligados a um sistema informatizado de ordenha.

A determinação dos teores de gordura e de proteína do leite foi realizada em amostras coletadas durante quatro ordenhas consecutivas no início de cada semana. As amostras foram enviadas ao Laboratório Interprofissional Leiteiro do Centro-oeste, Surgères, França. A correção do leite a 4\% de gordura foi calculada utilizando-se equação descrita pelo NRC (2001).

Para determinação do nível de aceitabilidade das silagens pelos animais, foi realizado um ensaio de velocidade de ingestão, quando os animais receberam silagem sem o concentrado durante 1 hora. Após este período, os comedouros foram pesados para obtenção do consumo. Essa avaliação foi realizada durante três dias consecutivos.

A granulometria das silagens foi determinada segundo recomendações de Melcion (2000), com auxílio de um separador de partículas, modelo AS200 digit-Retsch, no qual uma amostra de $50 \mathrm{~g}$ de silagem seca em estufa a $65^{\circ} \mathrm{C}$ durante 72 horas foi colocada no alto de um empilhamento de sete peneiras, dispostas em ordem decrescente $(19,0$; 8,$0 ; 4,0 ; 3,6 ; 2,8 ; 1,8$ e < $1,8 \mathrm{~mm}$ de crivo), e submetida a movimentos vibratórios durante cinco minutos. As frações retidas em cada peneira foram pesadas com o objetivo de determinar a distribuição granulométrica. Cinco repetições foram realizadas por amostra.

Extrações de suco das silagens foram realizadas a cada período experimental, por meio de amostragens de silagem fresca, para determinação do $\mathrm{pH}$.

Com o objetivo de determinar a composição química do ingerido e das rações, foram realizadas amostragens diárias das silagens, das sobras e dos concentrados. As amostragens de fezes, feitas diretamente no reto, foram realizadas uma vez ao dia, durante cinco dias consecutivos, após a saída da sala de ordenha, para determinação da digestibilidade aparente das rações. As fezes de cada animal foram embaladas em sacos plásticos, armazenadas e congeladas para posterior análise.

Os coeficientes da digestibilidade aparente das rações experimentais foram determinados segundo o método de amostragens parciais de fezes. O marcador interno utilizado foi a cinza insolúvel em ácido clorídrico (CIA), segundo Van Keulen \& Young (1977), com as seguintes equações:
Digestibilidade aparente da MS (DMS)

$$
D M S \%=100-100 *\left(\frac{\% \text { marcador na ração }}{\% \text { marcador nas fezes }}\right)
$$

Digestibilidade aparente dos nutrientes (Dnutr)

Dnutr \% $=100-100 *\left(\frac{\% \text { marcador na ração }}{\% \text { marcador nas fezes }}\right) *\left(\frac{\% \text { nutriente nas fezes }}{\% \text { nutriente na ração }}\right)$

As digestibilidades in vitro da matéria seca (DIVMS) das silagens foram obtidas pelo método enzimático, descrito por Aufrère (1982).

As amostras dos alimentos volumosos e das fezes foram secas em estufa a $65^{\circ} \mathrm{C}$ durante 72 horas. Ao final de cada período, as amostras de silagens, sobras e fezes foram agrupadas para formação de uma amostra composta por período e por animal. As amostras dos concentrados utilizados para equilibrar as rações foram obtidas uma vez em cada período, depois reagrupadas no final do experimento para formação de uma amostra representativa de todo o período experimental. As amostras compostas foram moídas com auxílio de um moinho tipo martelo com peneira de crivos de $1 \mathrm{~mm}$ e armazenadas em potes plásticos para posteriores análises em laboratório.

Os teores de matéria seca (MS), proteína bruta (PB), nitrogênio insolúvel em detergente ácido (NIDA), fibra em detergente neutro (FDN), fibra em detergente ácido (FDA), celulose bruta $(\mathrm{CB})$ e matéria orgânica $(\mathrm{MO})$ foram determinados na forragem verde e nas silagens, sobras e fezes (Tabela 2), segundo metodologia descrita pelo AOAC (1997).

Tabela 2 - Composição das dietas experimentais

\begin{tabular}{|c|c|c|c|}
\hline \multirow[b]{2}{*}{ Ingrediente } & \multicolumn{3}{|c|}{ Dieta basal ${ }^{1}$} \\
\hline & $\mathrm{SM}^{2}$ & $\mathrm{SG}^{3}$ & $\mathrm{SS}^{4}$ \\
\hline Silagem, \% & 85,30 & 83,70 & 82,40 \\
\hline Concentrado, \% & 14,70 & 16,30 & 17,60 \\
\hline \multicolumn{4}{|c|}{ Composição nutricional } \\
\hline MS, \% & 37,12 & 46,08 & 26,45 \\
\hline $\mathrm{EB}^{* *}$ & 4,30 & 4,35 & 4,31 \\
\hline $\mathrm{PB}, \%$ & 13,06 & 14,84 & 13,45 \\
\hline NIDA, \% & 2,27 & 3,01 & 2,16 \\
\hline FDN, \% & 35,75 & 43,12 & 48,53 \\
\hline FDA, \% & 17,60 & 21,75 & 24,15 \\
\hline Celulose bruta, $\%$ & 15,60 & 18,67 & 21,27 \\
\hline $\mathrm{MO}, \%$ & 92,76 & 92,12 & 91,59 \\
\hline CIA, \% & 1,59 & 1,27 & 1,18 \\
\hline
\end{tabular}

*Dados obtidos no Laboratório de Análises da UGAPF - INRA Poitou Charentes, França. ${ }^{1}$ Dieta basal: silagens (milho ou sorgo), concentrado rico em proteína (PROTIVAL ${ }^{\circledR}$, Centre Atlantique Aliments, Ceaux em Couhé, França), cevada ou uréia. ${ }^{2}$ Silagem de milho (SM); ${ }^{3}$ Silagem de sorgo granífero (SG); ${ }^{4}$ Silagem de sorgo sacarino (SS). ** Megacalorias $/ \mathrm{kg}$ de MS. 
A determinação da energia bruta (EB) foi realizada no Laboratório de Análises Químicas da Estação Experimental do INRA, localizado na cidade de Magneraud - França, com a utilização de uma bomba calorimétrica, sistema IKA ${ }^{\circledR}$ C7000.

As análises estatísticas foram realizadas de acordo com o modelo abaixo, utilizando-se o programa SAS (1989):

$$
\text { Yijkl }=\mu+S i+T j+T j * S i+T j * A k+E i j k l
$$

em que $\mathrm{Y}_{\mathrm{ikl}}=$ variável observada; $\mu=$ constante geral; $\mathrm{S}_{\mathrm{i}}=$ efeito da semana experimental ${ }^{\mathrm{i}} \cdots, \operatorname{com} \mathrm{i}=1 \mathrm{a} 13 ; \mathrm{T}_{\mathrm{j}}=$ efeito do tratamento experimental $~ \mathrm{j}^{\circ}$, com $\mathrm{j}=1$ (silagem de milho), 2 (silagem de sorgo granífero) e 3 (silagem de sorgo sacarino); $\mathrm{T}_{\mathrm{j}} * \mathrm{~S}_{\mathrm{i}}=$ efeito da interação tratamento*semana; $\mathrm{T}_{\mathrm{j}} * \mathrm{~A}_{\mathrm{k}}=$ efeito do animal hierarquizado no tratamento $(\mathrm{k})$; $\mathrm{E}_{\mathrm{ijkl}}=$ erro aleatório associado a cada observação.

Os efeitos de tratamento foram estimados com o $\mathrm{F}$ correspondente ao produto entre os quadrados médios do tratamento $\left(\mathrm{T}_{\mathrm{j}}\right)$ e o do efeito animal hierarquizado no tratamento $\left(\mathrm{T}_{\mathrm{j}} * \mathrm{~A}_{\mathrm{k}}\right)$, uma vez que se trata de um dispositivo com avaliações repetidas e que, segundo Little \& Hills (1978), os resultados de uma semana dependem dos valores da semana anterior.

\section{Resultados e Discussão}

Os valores médios obtidos para $\mathrm{pH}$ nas silagens de milho e sorgo (Tabela 3) encontram-se nos limites que caracterizam uma fermentação desejável e adequada para preservação do material (4,02 a 4,59). Segundo Keplin(1992), uma silagem de milho, para ser considerada de boa qualidade, deve apresentar de 7,1 a 8,0\% de PB. Os resultados obtidos neste trabalho foram inferiores ao preconizado por esse au tor. Corroborando informações de Keplin (1992), Flaresso et al. (2000) trabalharam com 13 cultivares de milho e 8 cultivares de sorgo e obtiveram médias de $8,3 \%$ para os cultivares de milho e 7,1\% PB para os de sorgo.

Os valores médios obtidos para as características das culturas de milho e dos sorgos (Tabela 4) comprovamque o corte do milho e das variedades de sorgo foi realizado em estágios mais avançados (29,2\% a 49,1\% de MS), quando os grãos podem ser denominados farináceos e farináceos duros, o que, segundo Le Gall et al. (1994), resultaria em silagens de melhor qualidade. Segundo esses autores, a maior participação de grãos na massa ensilada resultaria em melhor valor nutritivo, fato observado para a cultura do milho (48,5\% no teor de grãos). Contudo, o menor valor observado para o teor de grãos na cultura do sorgo sacarino $(10,3 \%)$ está relacionado à sua fisiologia, uma vez que esta cultura, ao contrário do sorgo granífero, se caracteriza não por produzir o máximo de grãos, e sim pelo alto teor de carboidratos não-estruturais que permanecem no caule e nas folhas na forma de açúcares solúveis, resultando em um alimento energético e de fácil conservação (Hale, 1970).

A cultura de sorgo supera em alguns aspectos a do milho, pois atinge maior produção de massa por área, principalmente em locais com solos de baixa fertilidade e pouca precipitação (Zago, 1991). Esta afirmação está de acordo com Legarto (2000), que, ao comparar os rendimentos

Tabela 3 - Composição química da forragem verde e das silagens

\begin{tabular}{|c|c|c|c|c|c|c|}
\hline \multirow[b]{2}{*}{ Composição } & \multicolumn{3}{|c|}{ Forragem verde } & \multicolumn{3}{|c|}{ Silagem } \\
\hline & $\mathrm{SM}^{1}$ & $\mathrm{SG}^{2}$ & $\mathrm{SS}^{3}$ & $\mathrm{SM}^{1}$ & $\mathrm{SG}^{2}$ & $\mathrm{SS}^{3}$ \\
\hline Matéria seca, \% & 33,20 & 49,10 & 29,20 & 35,24 & 45,87 & 26,19 \\
\hline Energia bruta ${ }^{* *}$ & 4,32 & 4,32 & 4,41 & 4,37 & 4,41 & 4,37 \\
\hline Proteína bruta, \% & 7,89 & 8,56 & 10,67 & 7,69 & 10,98 & 9,83 \\
\hline NIDA, $\%^{4}$ & 0,93 & 0,63 & 1,27 & 1,85 & 2,70 & 1,70 \\
\hline FDN, $\%^{5}$ & 40,62 & 49,38 & 49,20 & 38,19 & 47,40 & 54,58 \\
\hline Hemicelulose, $\%$ & 22,01 & 25,68 & 24,65 & 19,29 & 23,23 & 27,07 \\
\hline Lignina, $\%$ & 2,22 & 2,37 & 3,13 & 2,11 & 3,57 & 3,00 \\
\hline Celulose bruta, \% & 16,52 & 24,45 & 23,15 & 17,48 & 21,42 & 24,89 \\
\hline Matéria orgânica, \% & 95,52 & 94,37 & 94,32 & 95,24 & 94,42 & 93,75 \\
\hline CIA, $\%^{7}$ & - & - & - & 1,59 & 1,24 & 1,14 \\
\hline DIVMS, $\%^{8}$ & 76,43 & 67,56 & 66,34 & 74,25 & 69,73 & 65,92 \\
\hline $\mathrm{pH}$ & - & - & - & 4,02 & 4,59 & 4,08 \\
\hline
\end{tabular}

* Dados obtidos no Laboratório de Análises da UGAPF - INRA Poitou-Charentes, França.

1 Silagem de milho (SM).

2 Silagem de sorgo granífero (SG).

3 Silagem de sorgo sacarino (SS).

${ }^{4}$ Nitrogênio Insolúvel em detergente ácido (NIDA).

${ }^{5}$ Fibra em detergente neutro (FDN).

${ }_{7}^{6}$ Fibra em detergente ácido (FDA).

${ }^{7}$ Cinza insolúvel em ácido (CIA).

${ }^{8}$ Digestibilidade in vitro da matéria seca (DIVMS).

${ }^{* *} \mathrm{Mcal} / \mathrm{kg}$ de MS. 
Tabela 4 - Características da cultura de milho e dos sorgos no momento da ensilagem

\begin{tabular}{lccc}
\hline Item & $\begin{array}{c}\text { Cocagne }^{\circledR} \\
\text { Milho** }\end{array}$ & $\begin{array}{c}\text { Arakan }^{\circledR} \\
\text { Sorgo } \\
\text { granífero }\end{array}$ & $\begin{array}{c}\text { Top silo } \\
\text { Sorgo } \\
\text { sacarino }\end{array}$ \\
\hline MS planta inteira (\%) & 33,2 & 49,1 & 29,2 \\
MS espigas (ou panícula) (\%) & 54,6 & 62,9 & 46,1 \\
MS não espiga & 21,4 & 39,4 & 27,0 \\
(ou não panícula) (\%) & 48,5 & 33,4 & 10,3 \\
Teor em grãos (\% MS) & 18,4 & 13,4 & 11,7 \\
$\begin{array}{l}\text { Rendimento (toneladas de } \\
\text { MS/ha) }\end{array}$ & & & \\
\hline
\end{tabular}

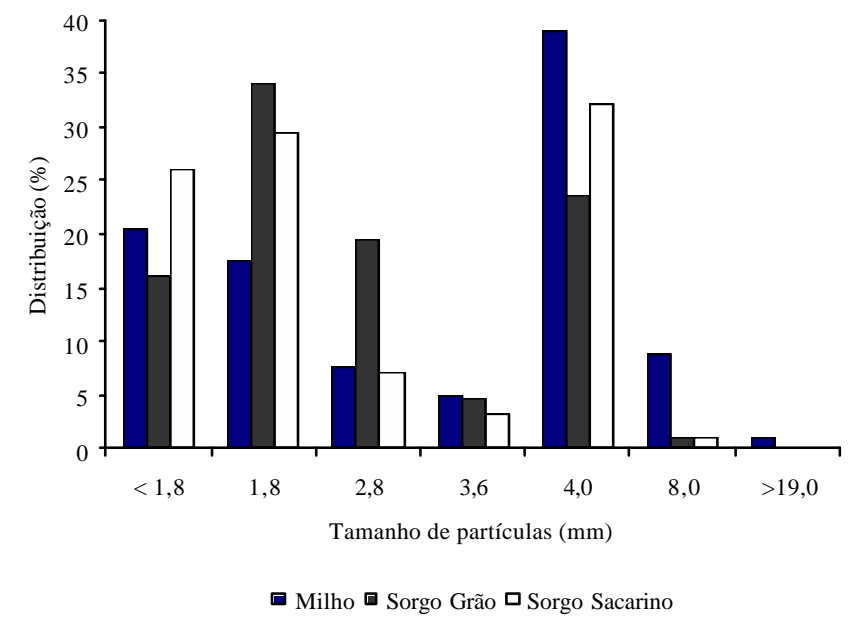

Figura 2 - Distribuição do tamanho de partículas das silagens de milho, sorgo granífero e sorgo sacarino (\%).

da cultura do sorgo em relação à cultura do milho realizado no norte de l'Aquitaine (França) pelo Institut de l'Elevage no período de 1988 a 1990, observou melhordesempenho do sorgo em situações de seca, com menos de $200 \mathrm{~mm}$ de água entre o início de maio e fim de setembro. Por outro lado, o milho tornou-se favorável em quantidade de água superior a $300 \mathrm{~mm}$.

Nesta pesquisa, apesar de o milho ter apresentado produção de matéria seca muito superior ( 5 a 7 toneladas de MS) à dos sorgos, os resultados comprovaram que as culturas de sorgo utilizadas neste trabalho tiveram bom rendimento em toneladas de MS/ha em relação ao milho, visto que não foram irrigadas e, doponto de vista climático, o ano de 2003 foi marcado por uma primavera amena e de poucas chuvas, seguida de um verão excepcionalmente quente (Figura 1).

A silagem de milho apresentou maior proporção de partículas de tamanho grande em relação às silagens de sorgo granífero e de sorgo sacarino (Figura 2). Entretanto, a presença de partículas superiores a $8 \mathrm{~mm}$ para o milho ensilado não influenciou as quantidades ingeridas pelos animais. Jarrige (1988) e Van Soest (1994) relataram que o tempo de ruminação (partículas $>5 \mathrm{~mm}$ ) limita a capacidade de ingestão.

Os animais alimentados com silagem de sorgo granífero apresentaram maior consumo $(\mathrm{P}<0,05)$ de silagem e ração total (kg de MS/dia) em comparação àqueles alimentados com as silagens de milho e de sorgo sacarino (Tabela 5). Além disso, o consumo de MS da silagem de milho foi superior $(\mathrm{P}<0,05)$ ao de silagem de sorgo sacarino.

A silagem de sorgo sacarino, em razão da sua maior proporção de parede celular (Tabela 3 ) em relação às outras silagens, pode ter contribuído para o efeito negativo sobre a ingestão de MS e, conseqüentemente, ter resultado em menor ingestão de energia. Esses resultados corroboram os obtidos por Dias et al. (2001), que atribuíram esse fenômeno ao enchimento do rúmen antes que todos os nutrientes necessários aos animais fossem ingeridos, como também à saturação da capacidade de ruminação, que reflete na limitação da produção de leite.

A ingestão de PB foi superior $(\mathrm{P}<0,05)$ entre as vacas alimentadas com silagem de sorgo granífero e semelhante entre aquelas alimentadas com as silagens de milho e de sorgo sacarino. A maior ingestão de PB entre as vacas alimentadas com silagem de sorgo granífero pode ser explicada pela maior ingestão total de MS e pela maior participação de grãos na dieta total, bem como pelo maior teor de PB neste tratamento (Tabela 2).

A ingestão de água foi semelhante $(\mathrm{P}>0,05)$ entre os animais alimentados com as silagens de milho $(71,91 \mathrm{~L} /$ animal/dia) e de sorgo granífero $(76,30 \mathrm{~L} / \mathrm{animal} / \mathrm{dia})$ e menor $(\mathrm{P}<0,05)$ entre aqueles alimentados com silagem de sorgo sacarino (56,95 L/animal/dia). O consumo de água observado está na faixa de consumo (14,2 a 171,4 L/animal/ dia) descrita por Meyer et al. (2004). Segundo esses autores, o menor valor observado para o consumo de água está relacionado a diversos fatores, entre eles, o nível de produção, a presença de cio e a temperatura ambiente, além de problemas sanitários do animal e da menor ingestão de MS, evidenciada neste trabalho, visto que a menor ingestão de água foi observada nos animais alimentados com silagem de sorgo sacarino, cuja ingestão de MS total foi a menor.

A técnica da velocidade de ingestão é normalmente empregada em ensaios de pastejo no intuito de avaliar a preferência do animal por determinadas espécies vegetais (Emile et al., 2001; Mayne et al., 2001).Por meio de adaptações desta técnica para animais estabulados, a taxa de ingestão de MS entre os animais alimentados com silagem de milho foi maior $(\mathrm{P}<0,05)$ que entre aqueles alimentados com as demais silagens (Tabela 5). Ainda, a taxa de ingestão de MS foi semelhante $(\mathrm{P}>0,05)$ entre os animais alimentados 
Tabela 5 - Ingestão média diária das silagens e das rações totais

\begin{tabular}{|c|c|c|c|c|c|c|}
\hline Item & $\mathrm{SM}^{1}$ & $\mathrm{EP}$ & $\mathrm{SG}^{2}$ & EP & $\mathrm{SS}^{3}$ & $\mathrm{EP}$ \\
\hline Ingestão de silagem, $\mathrm{kg} \mathrm{MS} / \mathrm{dia}$ & $17,02 b$ & 0,24 & $17,64 \mathrm{a}$ & 0,31 & $13,64 \mathrm{c}$ & 0,21 \\
\hline Ingestão total, kg MS/dia & $21,95 b$ & 0,22 & $22,98 \mathrm{a}$ & 0,32 & $19,43 \mathrm{c}$ & 0,20 \\
\hline Ingestão média MS, $100 \mathrm{~kg} \mathrm{PV} \mathrm{corrigido}$ & $3,93 \mathrm{~b}$ & 0,07 & $4,22 \mathrm{a}$ & 0,12 & $3,37 \mathrm{c}$ & 0,08 \\
\hline Proteína bruta $(\mathrm{PB}), \mathrm{kg} / \mathrm{dia}$ & $3,01 \mathrm{~b}$ & 0,02 & $3,54 \mathrm{a}$ & 0,04 & $2,99 \mathrm{~b}$ & 0,02 \\
\hline Energia bruta (EB), Mcal/dia & $84,43 \mathrm{~b}$ & 0,97 & $87,68 \mathrm{a}$ & 1,39 & $69,44 \mathrm{c}$ & 0,85 \\
\hline Fibra detergente neutro (FDN), $\mathrm{kg} / \mathrm{dia}$ & $7,78 \mathrm{c}$ & 0,08 & $9,71 \mathrm{a}$ & 0,15 & $8,87 \mathrm{~b}$ & 0,11 \\
\hline Ingestão de água, L/vaca/dia & $71,91 \mathrm{a}$ & 2,14 & $76,30 \mathrm{a}$ & 2,03 & $56,95 b$ & 0,98 \\
\hline Taxa de ingestão, $\mathrm{kg}$ MS/hora & $3,83 \mathrm{a}$ & 0,26 & $3,05 b$ & 0,24 & $2,90 \mathrm{~b}$ & 0,21 \\
\hline
\end{tabular}

a,b,c Médias seguidas de letras diferentes na mesma linha diferem-se $(P<0,05)$ pelo teste Tukey.

${ }^{1}$ Silagem de milho (SM); ${ }^{2}$ Silagem de sorgo granífero (SG); ${ }^{3}$ Silagem de sorgo sacarino (SS); Erro-padrão (EP).

Tabela 6 - Desempenho de vacas leiteiras alimentadas com silagem de sorgo granífero(SG), silagem de sorgo sacarino (SS) e silagem de milho (SM)

\begin{tabular}{|c|c|c|c|c|c|c|}
\hline Item & $\mathrm{SM}^{1}$ & EP & $\mathrm{SG}^{2}$ & $\mathrm{EP}$ & $\mathrm{SS}^{3}$ & $\mathrm{EP}$ \\
\hline Produção de leite total, kg/dia & $28,81 \mathrm{a}$ & 0,33 & $24,69 b$ & 0,37 & $24,14 b$ & 0,39 \\
\hline Produção corrigida ( $4 \%$ de gordura) & $30,65 \mathrm{a}$ & 0,51 & $25,63 b$ & 0,37 & $26,10 \mathrm{~b}$ & 0,46 \\
\hline Gordura no leite, $\mathrm{kg} / \mathrm{dia}$ & $1,28 \mathrm{a}$ & 0,03 & $1,05 \mathrm{c}$ & 0,02 & $1,09 \mathrm{~b}$ & 0,02 \\
\hline Proteína no leite, $\mathrm{kg} / \mathrm{dia}$ & $0,94 \mathrm{a}$ & 0,01 & $0,72 b$ & 0,01 & $0,73 b$ & 0,01 \\
\hline Gordura, $\%$ & $4,39 b$ & 0,06 & $4,31 b$ & 0,06 & $4,56 \mathrm{a}$ & 0,06 \\
\hline Proteína, \% & $3,25 \mathrm{a}$ & 0,02 & $2,97 \mathrm{c}$ & 0,03 & $3,05 b$ & 0,02 \\
\hline Peso vivo médio bruto (PVb), kg & $642,81 \mathrm{a}$ & 11,54 & $609,13 c$ & 6,75 & $625,44 b$ & 11,97 \\
\hline Peso vivo médio corrigido ( $\mathrm{PVc}), \mathrm{kg}$ & $556,32 \mathrm{a}$ & 10,94 & $521,78 b$ & 6,76 & $552,02 \mathrm{a}$ & 11,67 \\
\hline Ganho médio diário corrigido, $\mathrm{kg} / \mathrm{dia}$ & $0,07 \mathrm{a}$ & 0,14 & $-0,02 \mathrm{a}$ & 0,14 & $0,12 \mathrm{a}$ & 0,20 \\
\hline
\end{tabular}

a,b,c Médias seguidas de letras diferentes na mesma linha diferem-se $(P<0,05)$ pelo teste Tukey.

${ }^{1}$ Silagem de milho (SM); ${ }^{2}$ Silagem de sorgo granífero (SG); ${ }^{3}$ Silagem de sorgo sacarino (SS); Erro-padrão (EP).

com as silagens de sorgo granífero e de sorgo sacarino.No entanto, a utilização desta técnica para animais em confinamento deve ser aprimorada, pois, a partir do primeiro dia de avaliação, os animais se condicionaram a esperar pelo concentrado, adicionado 1 hora após avaliação.

A produção de leite total (kg/dia) e corrigida para $4 \%$ de gordura foi maior $(\mathrm{P}<0,05)$ para as vacas que consumiram silagem de milho $(28,81 ; 30,65)$ em comparação àquelas alimentadas com silagem de sorgo granífero $(24,69 ; 25,63)$ ou sorgo sacarino $(24,14 ; 26,10)$ (Tabela 6$)$. A produção de gordura $(\mathrm{kg} / \mathrm{dia})$ foi maior $(\mathrm{P}<0,05)$ para os animais alimentados com silagem de milho em comparação aos demais. Além disso, os animais que receberam silagem de sorgo sacarino apresentaram maior $(\mathrm{P}<0,05)$ porcentagem de gordura no leite em comparação àqueles alimentados com silagem de sorgo granífero. Para a produção de proteína do leite ( $\mathrm{kg} / \mathrm{dia})$, os animais alimentados com as silagens de sorgo granífero e de sorgo sacarino não diferiram $(\mathrm{P}>0,05)$ entre si, embora tenham apresentado produção menor $(\mathrm{P}<0,05)$ em comparação àqueles alimentados com silagem de milho.

A produção absoluta de gordura e proteína bruta do leite, no entanto, não é a medida mais adequada para comparações entre tratamentos. Assim, a porcentagem de gordura e de proteína do leite seria o parâmetro mais adequado para comparações. Nesse contexto, a porcentagem de gordura do leite foi maior $(\mathrm{P}<0,05)$ para os animais alimentados com silagem de sorgo sacarino e semelhante para aqueles alimentados com silagem de milho e silagem de sorgo granífero. A porcentagem de proteína foi maior $(\mathrm{P}<0,05)$ no leite dos animais alimentados com silagem de milho, intermediária no leite dos animais alimentados com silagem de sorgo sacarino e menor no leite daqueles alimentados com silagem de sorgo granífero.

Os resultados obtidos neste estudo com as silagens de sorgo (1,98 a 2,18 kg de gordura/dia e 1,39 a 1,45 kg de proteína/dia) foram inferiores aos descritos por Bal et al. (1997), ao avaliarem o desempenho de vacas leiteiras alimentadas com silagens de milho colhido em diferentes estádios de maturidade (leitoso/pastoso, $1 / 4$ pastoso, $2 / 3$ pastoso duro e vitrificado) $(1,14$ a $1,17 \mathrm{~kg}$ de gordura/dia e 1,12 a $1,17 \mathrm{~kg}$ de proteína/dia).

Entretanto, Dias et al. (2001) apresentaram resultados inferiores para gordura do leite $(3,55 \%$ silagem de milho, $3,43 \%$ silagem de sorgo estádio de emborrachamento e $3,62 \%$ silagem de sorgo granífero leitoso).

Os baixos teores de proteína na composição do leite dos animais alimentados com silagem de sorgo granífero estão diretamente relacionados ao valor energético da silagem. Segundo Le Gall et al. (1994), esse problema se 
Tabela 7 - Digestibilidade aparente (\%) de rações à base de silagens de milho, de sorgo granífero e de sorgo sacarino em vacas

\begin{tabular}{lcccccc}
\hline Variável (\%) & $\mathrm{SM}^{1}$ & $\mathrm{SE}$ & $\mathrm{SG}^{2}$ & $\mathrm{SE}$ & $\mathrm{SS}^{3}$ & $\mathrm{SE}$ \\
\hline MS, \% & $52,52 \mathrm{c}$ & 0,40 & $54,63 \mathrm{~b}$ & 0,53 & $63,65 \mathrm{a}$ & 0,45 \\
PB, \% & $51,87 \mathrm{c}$ & 0,65 & $57,96 \mathrm{~b}$ & 0,59 & $68,38 \mathrm{a}$ & 0,51 \\
EB ${ }^{* *}$ & $51,23 \mathrm{c}$ & 0,41 & $51,69 \mathrm{~b}$ & 0,58 & $60,84 \mathrm{a}$ & 0,49 \\
FDN, \% & $25,15 \mathrm{c}$ & 0,57 & $48,64 \mathrm{~b}$ & 0,73 & $54,93 \mathrm{a}$ & 0,63 \\
FDA, \% & $22,50 \mathrm{c}$ & 0,60 & $49,38 \mathrm{~b}$ & 0,69 & $52,91 \mathrm{a}$ & 0,74 \\
Hemicelulose, \% & $27,58 \mathrm{c}$ & 0,76 & $47,91 \mathrm{~b}$ & 0,84 & $56,84 \mathrm{a}$ & 0,71 \\
Celulose bruta, \% & $28,83 \mathrm{c}$ & 0,70 & $50,69 \mathrm{~b}$ & 0,97 & $55,09 \mathrm{a}$ & 0,76 \\
MO, \% & $53,92 \mathrm{c}$ & 0,40 & $55,75 \mathrm{~b}$ & 0,53 & $65,09 \mathrm{a}$ & 0,43 \\
\hline
\end{tabular}

a,b,c Médias seguidas de letras diferentes na mesma linha diferem-se $(\mathrm{P}<0,05)$ pelo teste Tukey.

${ }^{1}$ Silagem de milho (SM); ${ }^{2}$ Silagem de sorgo granífero $(\mathrm{SG}){ }^{3}$ Silage de sorgo sacarino (SS); Erro-padrão (SE). diminuiria as perdas de nitrogênio do rúmen. Além disso, segundo Nocek (1988), a utilização dos compostos da parede celular exige uma interação dinâmica entre o animal, a população microbiana e a dieta.

\section{Conclusões}

As silagens de sorgo apresentaram potencial de produção inferior ao do milho, entretanto, a rusticidade e a capacidade de adaptação a condições limitantes de crescimento, como temperaturas elevadas e escassez de água, continuam sendo os principais fatores que caracterizam os sorgos.

\section{Literatura Citada}

deve à dificuldade dos microrganismos do rúmen em atacar os grãos, o que resulta em escape de energia disponível. Uma alternativa viável sugerida pelos autores seria ensilar o sorgo granífero em estádio mais precoce (28-32\% MS), o que favorece o ataque e a degradação dos grãos inicialmente durante a fermentação da silageme, depois, no rúmen.

A variação do peso corporal durante o período de coleta de informações sobre a produção e composição do leite foi próxima de zero e não diferiu $(\mathrm{P}>0,05)$ entre tratamentos, o que indica utilização das reservas corporais para manutenção da produção leiteira. Resultados semelhantes foram observados por Emile \& Barrière (1992), Le Gall et al. (1994) e Barrière \& Emile (1995).

As dietas com silagem de milho e de sorgo granífero foram aquelas de menor $(\mathrm{P}<0,05)$ digestibilidade dos nutrientes (MS, PB, EB, FDN, FDA, HEM, CB e MO) (Tabela 7), que foi superior $(\mathrm{P}<0,05)$ para a dieta com silagem de sorgo granífero em comparação à dieta à base de silagem de milho. A maior $(\mathrm{P}<0,05)$ digestibilidade da ração à base de silagem de sorgo sacarino estaria relacionada: ao menor tamanho de partículas, pois, segundo Buxtonton \& Kolver, (1997), citados por Bezerra et al. (2002), as menores partículas alimentares são digeridas a taxas mais rápidas porque apresentam maior área de superfície exposta por volume de tecido; e ao maior teor de carboidratos solúveis da silagem, uma vez que a digestibilidade tende a aumentar de acordo com os teores de carboidratos solúveis da planta (Ferreira, 2001).

Ressalta-se que a maior digestibilidade da ração à base de silagem de sorgo sacarino pode também estar relacionada à melhor sincronização de metabólitos ruminais (Sinclair et al., 1995) e à maior qualidade do volumoso (principal fonte de FDN e FDA), o que pode promover elevados índices de digestibilidade dos nutrientes. Desse modo, uma sincronização entre proteínas e carboidratos
AUFRERE, J. Etude de la prévision de la digestibilité des fourrages par une méthode enzymatique. Annales de Zootechnie, v.31, n.2, p.111-130, 1982 .

ASSOCIATION OF OFFICIAL ANALYTICAL CHEMISTS - AOAC. Official methods of analysis. 16.ed. 3.rev. Washington, D.C.: 1997. method 991.36.

BAL, M.A.; COORS, J.G.; SHAVER, R.D. Impact of the maturity of corn for use as silage in the diets of dairy cows on intake, digestion, and milk production. Journal of Dairy Science, v.80, p.2497-2503, 1997.

BARRIÈRE, Y.; ÉMILE, J.C. Effets du génotype de maïs ensilage sur les performances zootechniques de vaches laitières. INRA Production Animale, v.8, n.5, p.315-320, 1995.

BEZERRA, E.S.; QUEIROZ, A.C.; MALDONADO, F. et al. Efeito do perfil granulométrico das partículas dietéticas sobre parâmetros de desempenho de vacas leiteiras em lactação. Revista Brasileira de Zootecnia, v.31, n.3, p.1511-1520, 2002 (supl.).

CHILLIARD, Y.; REMOND, B.; AGABRIEL, J. et al. Variations du contenu digestif et des réserves corporelles au cours du cycle gestation-lactation. Bulletin Technique CRZV Theix INRA, v.70, p.117-131, 1987.

COLEMAN, O.H. Syrup and Sugar from Sweet Sorghum. In: WALL, J.S.; ROSS, W.M. (Eds.) Sorghum production and utilization. London: 1970. p.416-440.

DIAS, A.M.A.; BATISTA, A.M.V.; FERREIRA, M.A. et al. Efeito do estádio vegetativo do sorgo (Sorghum bicolor, L. Moench) sobre a composição química da silagem, consumo, produção e teor de gordura do leite para vacas em lactação, em comparação à silagem de maïs (Zea mays L.). Revista Brasileira de Zootecnia, v.30, n.6, p.2086-2092, 2001 (supl.).

EMILE, J.C.; SURAULT, F.; HAZARD, L. et al. Estimer les vitesses d'ingestion au pasturage avec des vaches laitières. In: ACTES DES JOURnÉES DE L'AFPF, 2001, Paris. Actes... Paris: Association Française pour la Production Fourragère, 2001. A16.

EMILE, J.C.; BARRIÈRE, Y. Effets de la teneur en grain de l'ensilage de maïs sur les performances zootechniques de vaches laitières. INRA Productions Animales, v.5, n.2, p.113-120, 1992.

FERREIRA, J.J. Características qualitativas e produtivas da planta de milho e sorgo para silagem In: PRODUÇÃO E UTILIZAÇÃO DE SILAGEM DE MILHO E SORGO, 2001, Sete Lagoas. Anais... Sete Lagoas: 2001. p.383-404.

FLARESSO, J.A.; GROSS, C.D.; ALMEIDA, E.X. Cultivares de milho (Zea mays L.) e sorgo (Sorghum bicolor (L.) Moench.) para ensilagem no Alto Vale bdo Itajaí, Santa Catarina. Revista Brasileira de Zootecnia, v.29, n.6, p.1608-1615, 2000. 
HALE, W.H., Sorghum grain in ruminant nutrition In: WALL, J.S.; ROSS, W.M. (Eds.) Sorghum production and utilization. London: 1970. p.507-533.

INSTITUT D'ELEVAGE, ARPEB. L'utilisation par les vaches laitière du sorgho grain ensilé en plante entière. Paris: 1990. n.92081.

LE GALL, A.; LEGARTO, J.; RAVAIL, J. et al. Sorgho grain ensilage. Paris: Institut d'Elevage, 1994. 28p.

LEGARTO, J. L'utilisation en ensilage plante entière des sorghos grains et sucriers: intérêt et limites pour les régions sèches. Fourrages, n.163, p.323-338, 2000.

LITTLE, T.M.; HILLS, F.J. Subplot as repeated observations. In: (Eds.) Agricultura experimentation, design and analysis. New York: John Wiley \& Sons, 1978. p.125-137.

KEPLIN, L.A.S. Recomendação de sorgo e milho (silagem) safra 1992/ 93. Revista Batavo CCLPL, Ano I, n.8, p.16-19, 1992. (Encarte Técnico).

JARRIGE, R. Alimentation des bovins, ovins et caprins. Paris: INRA, $1988.471 \mathrm{p}$

MAYNE, C.S.; PATTERSON, M.; McGILlOWAY, D. et al. Effet de différentes variétés de ray-grass anglais sur la vitesses d'ingestion au pasturage. In: ACTES DES JOURNÉES DE L'AFPF. 2001, Paris. Actes... Paris: Association Française pour la Production Fourragère, 2001. A17.

McDONALD, P.; HENDERSON, N.; HERON, S. The biochemistry of silage. 2.ed. Marlow: Chalcombe Publications, 1991. 339p.

MELCION, J.P. La granulométrie de l'aliment: principe, mesure et obtention. INRA Productions Animales, v.13, n.2, p.81-97, 2000 .

MEYER, U.; EVERINGHOFF, M.; GÄDEKEN, D. et al. Investingations on the water intake of lactating dairy cows. Livestock Production Science, v.90, p.117-121, 2004.
MIZUBUTI, I.Y.; RIBEIRO, E.L.A.; ROCHA, M.A. et al. Consumo e digestibilidade aparente das silagens de milho (Zea mays L.), sorgo (Sorghum bicolor L. Moench) e girassol (Helianthus annuus L.). Revista Brasileira de Zootecnia, v.31, n.1, p.267-272, 2002.

NATIONAL RESEARCH COUNCIL - NRC. Nutrient requirements of dairy cattle. 7.ed. Washington, D.C: National Academy of Sciences, 2001. 381p.

NOCEK, J.E. Production research papers. Jounal of Dairy Science, v.71, n.8, p.2051-2069, 1988.

STATISCAL ANALYSIS SYSTEM - SAS. User's guide. Release 6.04. Cary: Institute Statistical Analyses System, 1989 (CD-ROM).

SAUVANT, D. Granulométrie des rations et nutrition du ruminant INRA Productions Animales, v.13, n.2, p.99-108, 2000

SINCLAIR, L.A.; GAINSWORTHY, P.C.; NEWBOLD, J.R. Effect of synchronizing the rate of dietary energy and nitrogen release in diets with a similar carbohydrate composition on rumen fermentation and microbial protein synthesis in in sheep. Journal Agriculture Science, v.124, p.463-472, 1995.

SOUZA, V.G.; PEREIRA, O.G., MORAES, S.A. et al. Valor nutritivo de silagens de sorgo. Revista Brasileira de Zootecnia, v.32, n.3, p.753-759, 2003.

Van SOEST, P.J. Nutritional ecology of the ruminant. 2.ed. New York: Cornell University Press, 1994. 476p.

Van KEULEN, J.; YOUNG, B.A. Evaluation of acid-insoluble ash as a marker in ruminant digestibility studies. Journal of Animal Science, v.44, n.2, p.283-28, 1977.

ZAGO, C.P.; POZAR, G. Cultura do sorgo para produção de silagem de alto valor nutritivo. In: SIMPÓSIO SOBRE NUTRIÇÃO DE BOVINOS, 4., 1991, Piracicaba. Anais...Piracicaba: Fundação de Estudos Agrários Luiz de Queiroz, 1991. p.169-217. 